\title{
Evaluasi kualitas estetika dan daya dukung Taman Bukit Bougenville Kota Singkawang
}

\author{
Chandra ${ }^{1}$, Agus Ruliyansyah ${ }^{1}$, Muhammad Pramulya ${ }^{1}$ \\ 1. Agroteknologi, Fakultas Pertanian, Universitas Tanjungpura, Indonesia \\ E-mail: chandratolen@gmail.com
}

\begin{abstract}
Abstrak
Evaluation of Aesthetical Quality and Carrying Capacity Bougenville Hill Park City of Singkawang. Bougenville Hill Park is part of the Green Open Space of the city that has ecological, social, economic and aesthetic functions. Aesthetic function is related to the value of beauty and becomes the main attraction for visitors. The purpose of this research is to determine and assess the quality of the park, determine the level of beauty based on respondents' perceptions, park carrying capacity analysis and evaluate the quality of the landscape based on the estimates of the beauty and carrying capacity of Bougenville Hill Park. This research used Scenic Beauty Estimation (SBE) method for evaluation of landscape aesthetic quality and Cifuentes (1992) method with physical carrying capacity for calculation of carrying capacity. The results show the landscape with the lowest SBE value based on the assessment of student and visitor respondents are in landscape 1. Landscapes with the highest SBE score based on students' SBE ratings are in landscape 12. While based on the assessment of visitor SBE, landscape with the highest SBE value is found in landscape 20. Based on the calculation of carrying capacity, the threshold of visitors of Bougenville Hill Park that can be done in 1 day is 72 people who move within the 6 ha area. Some management recommendations are proposed to maintain and improve the aesthetic quality and carrying capacity of Bougenville Hill Park such as maintenance and conservation measures.
\end{abstract}

Keywords: Aesthetical Quality, Carrying Capacity, Bougenville Hill

\section{Pendahuluan}

Taman Bukit Bougenville merupakan salah satu objek wisata yang populer di Kota Singkawang. Keindahan dan nuansa natural taman menjadi daya tarik utama bagi pengunjung. Pengunjung yang datang berasal dari dalam dan luar Kota Singkawang. Jumlah kunjungan akan meningkat pada akhir pekan dan saat libur sekolah.

Taman Bukit Buogenville merupakan bagian dari Ruang Terbuka Hijau kota yang memiliki fungsi ekologis, sosial, ekonomi dan estetika. Fungsi ekologis merupakan penyeimbang lingkungan alam dengan lingkungan buatan. Fungsi sosial dan ekonomi sebagai ruang berekreasi dan wisata, serta memberikan nilai keuntungan ekonomi bagi pengelola dan kota. Fungsi estetika berkaitan dengan nilai kendahan dan menjadi daya tarik utama untuk pengunjung (Dirjen Penataan Ruang, 2006).

Menurut Daniel dan Boster (1976) keindahan pemandangan lanskap merupakan salah satu sumber daya alam yang sangat penting walaupun secara obyektif keindahan pemandangan sulit diukur karena bersifat kualitatif, namun dengan menggunakan metode Scenic Beauty Estimation (SBE) penilaian secara kualitatif tersebut dapat ditransformasikan menjadi nilai kuantitatif. Metode SBE mengukur preferensi masyarakat dengan penilaian melalui sistem rating terhadap slide foto dengan menggunakan kuisioner.

Daya dukung taman merupakan aspek yang sangat penting dalam mengelola taman. Jumlah pengunjung yang melebihi daya dukung dapat menyebabkan kerusakan komposisi dan elemen penyusun taman sehingga fungsi dan kualitas taman menjadi turun. Agar taman Bukit Bougenville tetap dapat berfungsi secara optimal maka perlu dilakukan Evaluasi Kualitas Estetika dan Daya Dukung Taman Bukit Bougenville di Kota Singkawang.

\section{Metode}

Penelitian ini dilaksanakan di Taman Bukit Bougenville yang terletak di Desa Sijangkung, 6 km dari Kota Singkawang. Penelitian ini dilakukan dari tanggal 27 Juli sampai 2 November 2017. Penelitian ini 
menggunakan metode Scenic Beauty Estimation (SBE) untuk evaluasi kualitas estetika lanskap dan metode Cifuentes (1992) dengan pendekatan daya dukung fisik (Physical Carrying Capacity) untuk perhitungan daya dukung. Pelaksanaan evaluasi kualitas estetika lanskap dilakukan dengan tahapan: pemilihan lokasi, pemotretan, seleksi foto, penilaian oleh responden, perhitungan nilai SBE dan penentuan tingkat kelas. Sedangkan evaluasi daya dukung dilakukan dengan pendekatan daya dukung fisik (Physical Carrying Capacity) untuk mengetahui ambang batas kunjungan yang dapat dilakukan dalam 1 hari. Peta lokasi Taman Bukit Bougenville dapat dilihat pada Gambar 1 dibawah ini.

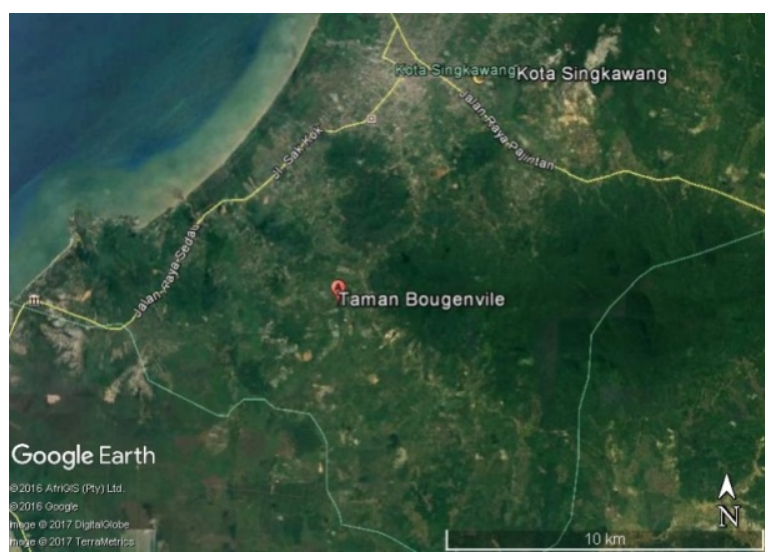

Sumber : Google Earth Pro

Gambar 1. Peta Lokasi Penelitian

3. Hasil dan Pembahasan

a. Penentuan dan Penilaian Kualitas Estetika Taman Bukit Bougenville

1. Pemilihan Tapak (Vantage Point)

Berdasarkan hasil pengamatan, vantage point yang terpilih di lokasi Taman Bukit Bougenville adalah sebanyak 20 tapak.

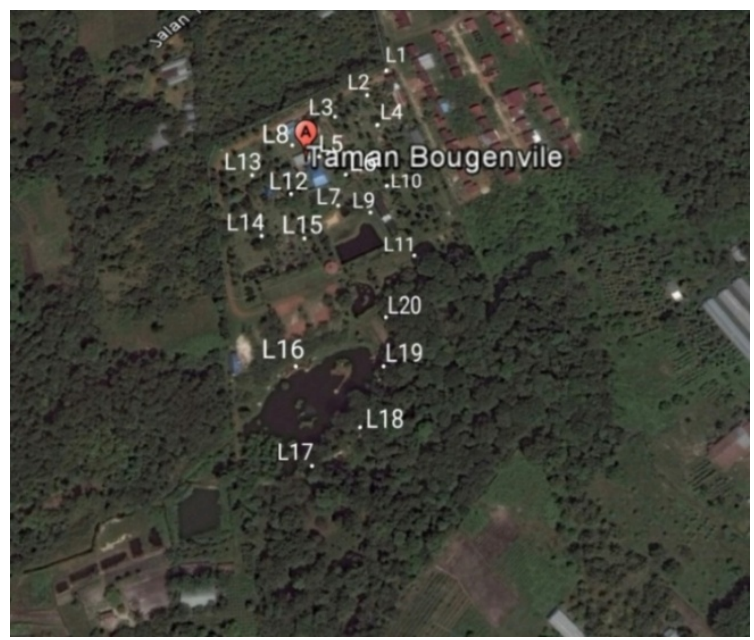

Sumber : Google Earth Pro

Gambar 2. Vantage Point Taman Bukit Bougenville

2. Penilaian Kualitas Estetika Taman Bukit Bougenville

Berdasarkan hasil penilaian kualitas estetika oleh responden mahasiswa dan responden pengunjung terhadap 20 tapak yang terpilih, didapat nilai SBE lanskap Taman Bukit Bougenville sebagai berikut. 


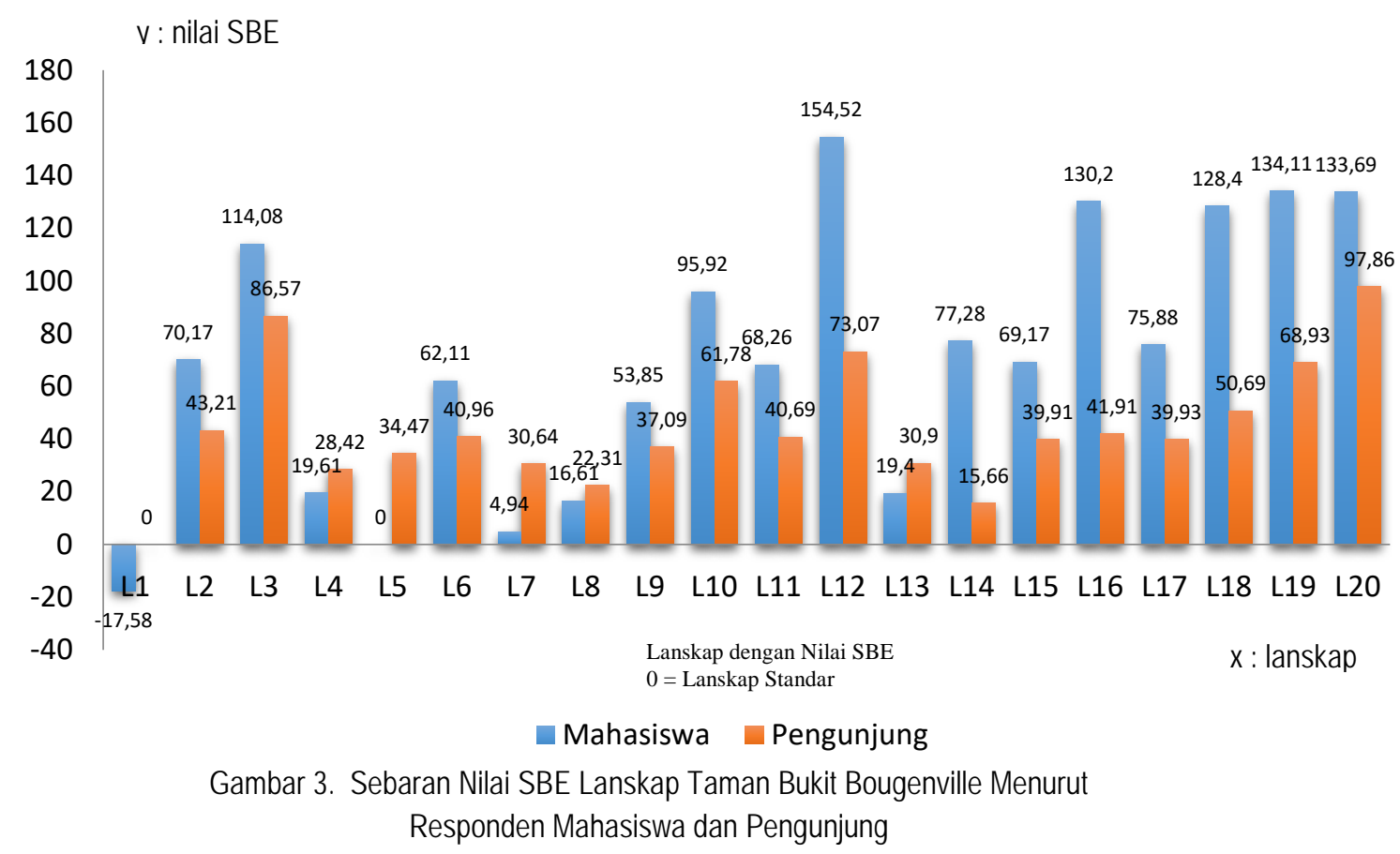

\section{b. Penentuan Tingkat Kelas Berdasarkan Persepsi Responden}

Seluruh nilai SBE yang telah diperoleh selanjutnya dikelompokkan berdasarkan kualitas estetika rendah, sedang, dan tinggi menggunakan jenjang sederhana (simplified rating).

Tabel 1. Klasifikasi Tingkat Kelas Kualitas Estetika Rendah, Sedang dan Tinggi Menggunakan Responden Mahasiswa

\begin{tabular}{cc}
\hline Nilai SBE & Kategori \\
\hline$-17,58$ s/d 57,36 & rendah \\
57,37 s/d 114,73 & sedang \\
114,74 s/d 154,52 & tinggi \\
\hline
\end{tabular}

Tabel 2. Klasifikasi Tingkat Kelas Kualitas Estetika Rendah, Sedang dan Tinggi Menggunakan Responden Pengunjung

\begin{tabular}{cc}
\hline Nilai SBE & Kategori \\
\hline 0 s/d 32,62 & rendah \\
32,63 s/d 65,25 & sedang \\
65,26 s/d 97,86 & tinggi \\
\hline
\end{tabular}

Tabel 3. Tingkat Kelas Lanskap Taman Bukit Bougenville Menggunakan Responden Mahasiswa dan Pengunjung

\begin{tabular}{ccccc}
\hline \multirow{2}{*}{ Lanskap } & \multicolumn{2}{c}{ Nilai SBE } & \multicolumn{2}{c}{ Kategori } \\
& Mahasiswa & Pengunjung & Mahasiswa & Pengunjung \\
\hline 1 & $-17,58$ & 0 & rendah & rendah \\
2 & 70,17 & 43,21 & sedang & sedang \\
3 & 144,08 & 86,57 & tinggi & tinggi \\
\hline
\end{tabular}


Lanjutan Tabel 3

\begin{tabular}{ccccc}
\hline \multirow{2}{*}{ Lanskap } & \multicolumn{2}{c}{ Nilai SBE } & \multicolumn{2}{c}{ Kategori } \\
& Mahasiswa & Pengunjung & Mahasiswa & Pengunjung \\
\hline 4 & 19,61 & 28,42 & rendah & rendah \\
5 & 0 & 34,47 & rendah & sedang \\
6 & 62,11 & 40,96 & sedang & sedang \\
7 & 4,94 & 30,64 & rendah & rendah \\
8 & 16,61 & 22,31 & rendah & rendah \\
9 & 53,85 & 37,09 & rendah & sedang \\
10 & 95,92 & 61,78 & sedang & sedang \\
11 & 68,26 & 40,69 & sedang & sedang \\
12 & 154,52 & 73,07 & tinggi & tinggi \\
13 & 19,4 & 30,9 & rendah & rendah \\
14 & 77,28 & 15,66 & sedang & rendah \\
15 & 69,17 & 39,91 & sedang & sedang \\
16 & 130,2 & 41,91 & tinggi & sedang \\
17 & 75,88 & 39,93 & sedang & sedang \\
18 & 128,4 & 50,69 & tinggi & sedang \\
19 & 134,11 & 68,93 & tinggi & tinggi \\
20 & 133,69 & 97,86 & tinggi & tinggi \\
\hline
\end{tabular}

\section{c. Analisis Daya Dukung Taman Bukit Bougenville}

Berdasarkan hasil perhitungan daya dukung menggunakan pendekatan daya dukung fisik, didapat nilai PCC adalah 2769,23 ha. Jumlah pengunjung sebesar 32741 selama tahun 2016 dibagi nilai PCC sehingga didapat kapasitas tampung wisatawan sebesar 12 orang/ha. Nilai ini mengandung arti bahwa setiap 1 ha luas area yang digunakan untuk wisata mampu menampung 12 orang, dengan tetap memperoleh kenyamanan secara fisik alam dalam berwisata. Taman Bukit Bougenville memiliki luas 6 ha, sehingga didapat nilai ambang batas pengunjung yang dapat dilakukan dalam 1 hari adalah 72 orang.

\section{d. Evaluasi Kualitas Lanskap Berdasarkan Penduga Keindahan dan Daya Dukung Taman Bukit Bougenville}

1. Evaluasi Kualitas Estetika Menggunakan Metode Scenic Beauty Estimation dengan Responden Mahasiswa dan Pengunjung

Berdasarkan hasil penilaian SBE, lanskap Taman Bukit Bougenville yang menggunakan responden mahasiswa memiliki nilai antara -17,58 sampai dengan 154,52. Dari hasil penilaian SBE mahasiswa didapat lanskap dengan nilai SBE terendah terdapat pada lanskap 1 dan tertinggi pada lanskap 12. Nilai SBE terendah $-17,58$ pada lanskap 1 sedangkan nilai SBE tertinggi 154,52 pada foto lanskap 12. Sedangkan berdasarkan hasil penilaian SBE menggunakan responden pengunjung, lanskap Taman Bukit Bougenville memiliki nilai antara 0 sampai dengan 97.86 . Dari hasil penilaian SBE pengunjung didapat lanskap dengan nilai SBE terendah terdapat pada lanskap 1 dan tertinggi pada lanskap 20. Nilai SBE terendah 0 pada lanskap 1 sedangkan nilai SBE tertinggi 97.86 pada foto lanskap 20. Pada lanskap dengan nilai SBE terendah berarti lanskap ini menunjukkan kualitas visual yang rendah dan paling tidak disukai responden. Sedangkan pada lanskap dengan nilai SBE tertinggi menunjukkan kualitas visual yang tinggi dan disukai oleh responden (Daniel and Boster, 1976).

Lanskap dengan nilai SBE terendah berdasarkan penilaian responden mahasiswa dan pengunjung terdapat pada lanskap 1. Lanskap 1 memiliki nilai SBE terendah karena didominasi oleh bangunan dan sedikit vegetasi serta kualitas fisik bangunan yang kurang baik sehingga responden menilai lanskap ini rendah. Bangunan dengan kualitas fisik yang kurang baik pada suatu lanskap cenderung menurunkan kualitas estetika. Hal ini diperkuat oleh pernyataan Ruswan (2006) bahwa lanskap dengan kualitas estetika rendah didominasi oleh elemen bangunan dengan kualitas bangunan kurang baik dan kurang menarik. Lanskap dengan nilai SBE 
tertinggi berdasarkan penilaian SBE mahasiswa terdapat pada lanskap 12. Lanskap 12 memiliki elemen vegetasi yang mendominasi dibandingkan elemen lainnya. Vegetasi yang rimbun pada lanskap ini memberi kesan sejuk dan nyaman. Hal ini sesuai dengan penelitian Meliawati (2003) bahwa karakter yang menonjol dari lanskap dengan kualitas estetika tinggi adalah proporsi vegetasi yang cukup dominan, sehingga terkesan teduh dan nyaman. Berbeda dengan hasil penilaian SBE mahasiswa, lanskap dengan nilai SBE tertinggi berdasarkan penilaian SBE pengunjung terdapat pada lanskap 20. Lanskap 20 memiliki vegetasi yang cukup mendominasi dengan penataan yang baik, indah dan menarik sehingga memberi kesan yang asri dan sejuk. Hal ini sesuai dengan penelitian Hendriawati (2011), bahwa kualitas yang baik dicapai dengan kondisi vegetasi yang penataannya rapi sehingga memiliki bentuk yang indah. Bangunan yang ada pada lanskap juga memiliki kualiatas visual yang baik, bersih dan menarik sehingga pengunjung menilai lanskap ini tinggi. Hal ini sesuai dengan penelitian Hendriawati (2011) bangunan dapat mempengaruhi nilai kualitas estetik apabila dilihat dari keadaan bangunan itu sendiri. Bangunan yang teratur dengan baik, menarik, dan bersih akan memberikan nilai kualitas estetik yang tinggi.
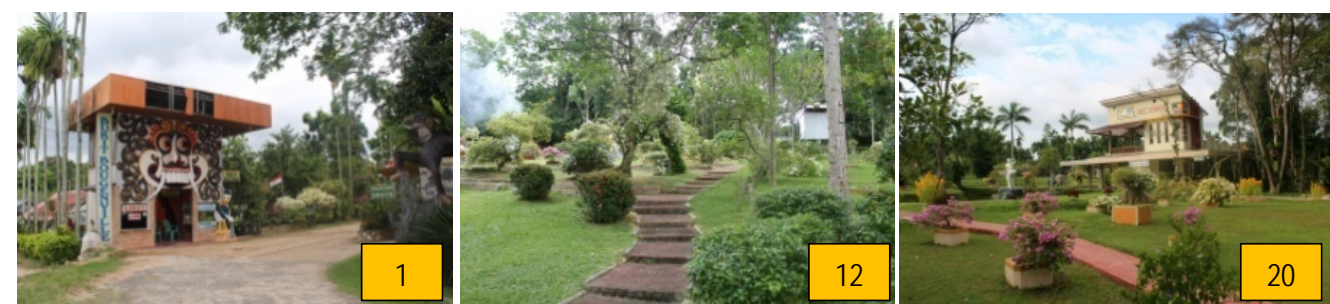

Gambar 4. Lanskap Kualitas Terendah (L1), Lanskap Kualitas Tertinggi

Responden Mahasiswa (L12) dan Responden Pengunjung (L20)

Seluruh nilai SBE yang telah diperoleh selanjutnya dikelompokkan berdasarkan kualitas estetika rendah, sedang, dan tinggi. Berdasarkan hasil penilaian SBE mahasiswa lanskap kualitas rendah memiliki nilai SBE $<57.37$, lanskap kualitas sedang memiliki nilai SBE antara 57.37 sampai 114.73 dan lanskap kualitas tinggi memiliki nilai SBE $>114.73$. Sedangkan hasil penilaian SBE pengunjung lanskap kualitas rendah memiliki nilai $\mathrm{SBE}<32.63$, lanskap kualitas sedang memiliki nilai SBE antara 32.63 sampai 65.25 dan lanskap kualitas tinggi memiliki nilai SBE > 65.25.

a. Lanskap dengan kualitas estetika rendah

Lanskap dengan kualitas estetika rendah terlihat dari dominasi bangunan dan perkerasan yang lebih tinggi dibandingkan vegetasi. Vegetasi yang ada pada lanskap juga tidak tertata dengan baik dan kurang terawat.. Lanskap 1, lanskap 4, lanskap 7, lanskap 8 dan lanskap 13 merupakan lanskap yang memiliki estetika rendah.
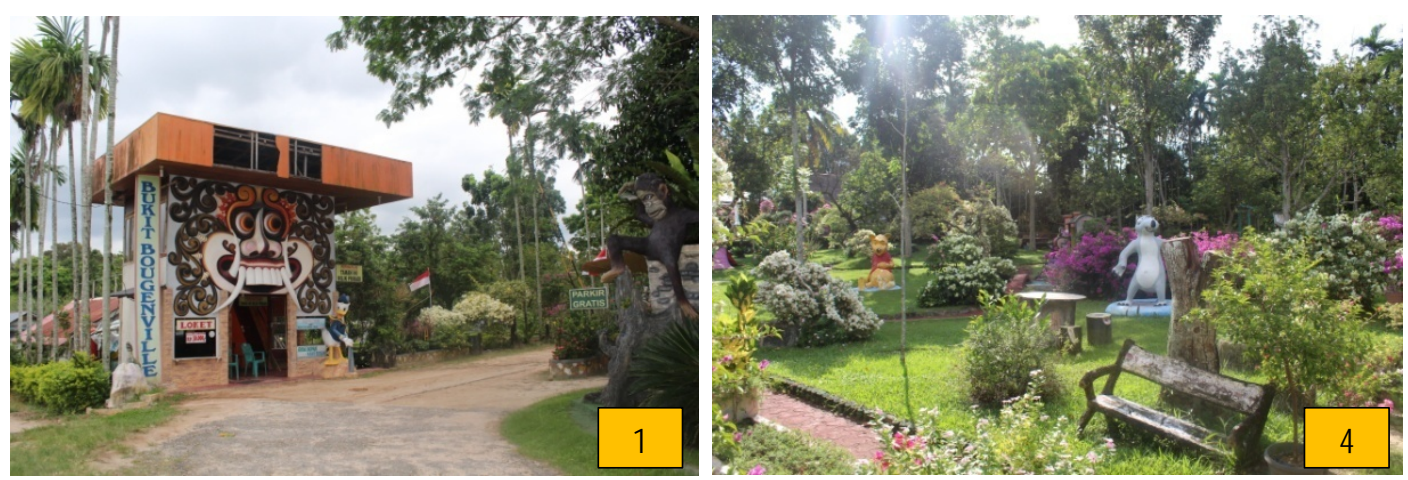


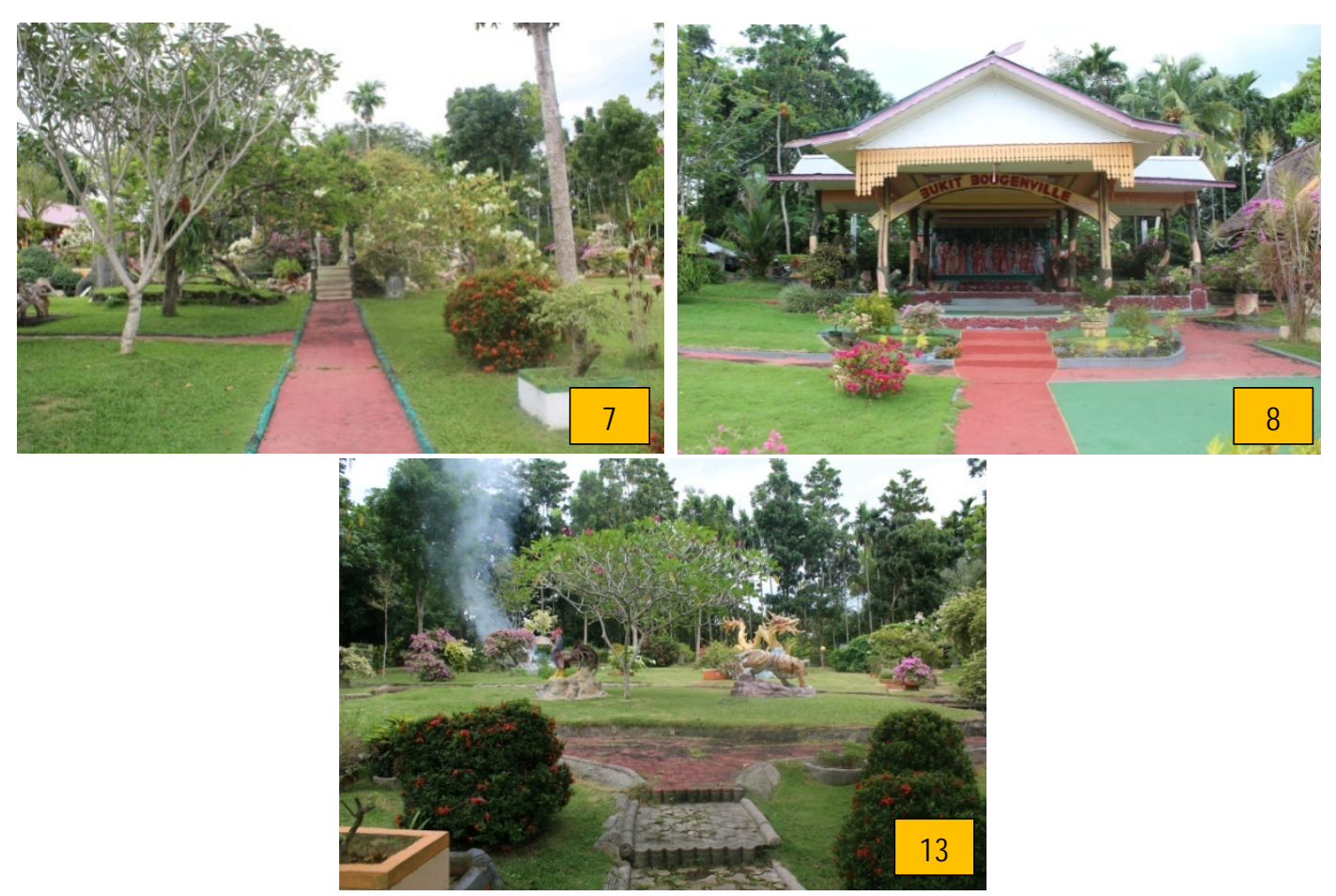

Gambar 5. Lanskap dengan Kualitas Estetika Rendah

\section{b. Lanskap dengan kualitas estetika sedang}

Karakter yang terlihat dari lanskap estetika sedang memiliki proporsi elemen vegetasi, bangunan dan perkerasan yang cukup seimbang namun penataannya kurang rapi. Lanskap 2, lanskap 6, lanskap 10, lanskap 11, lanskap 15 dan lanskap 17 merupakan lanskap dengan kualitas estetika sedang.
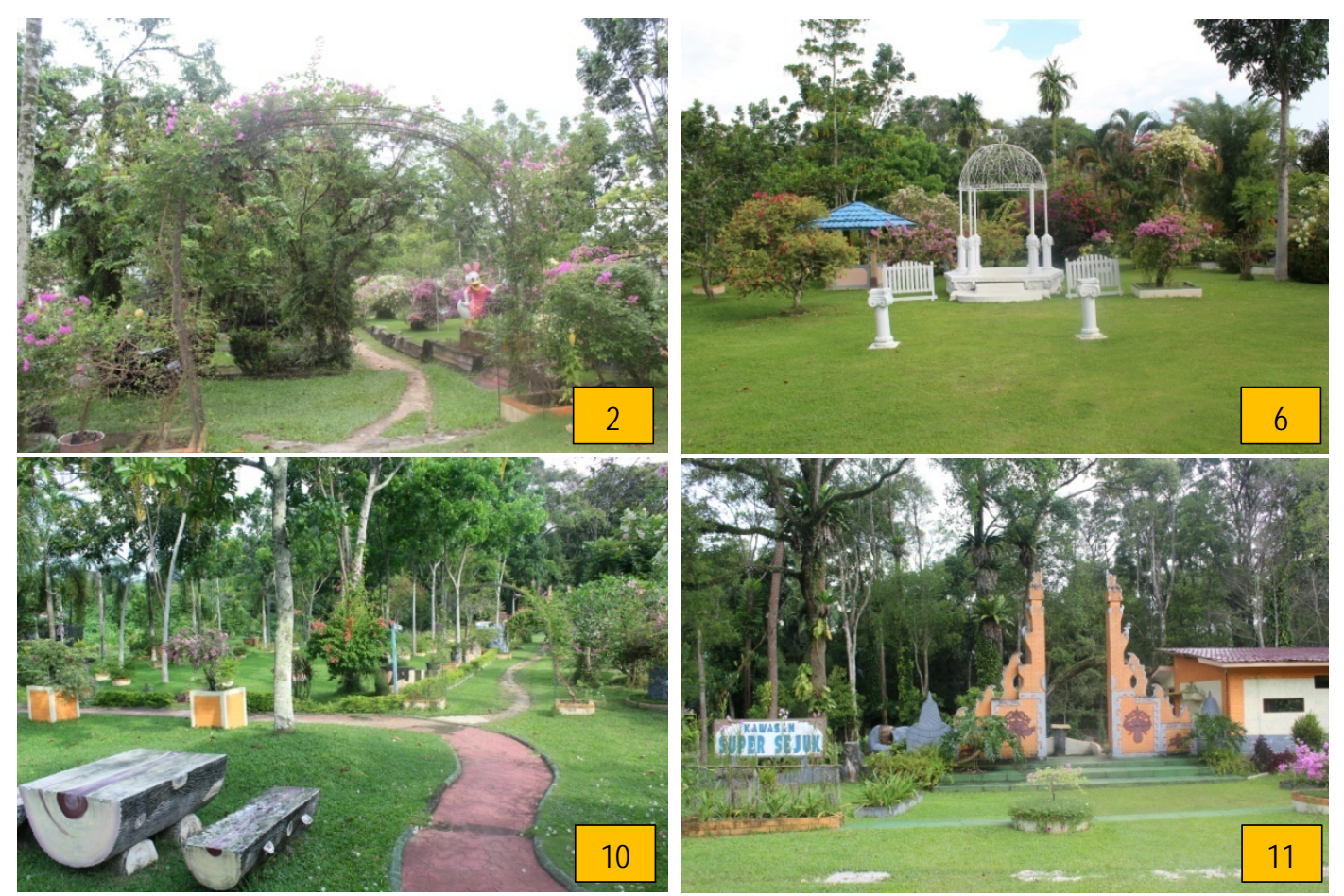

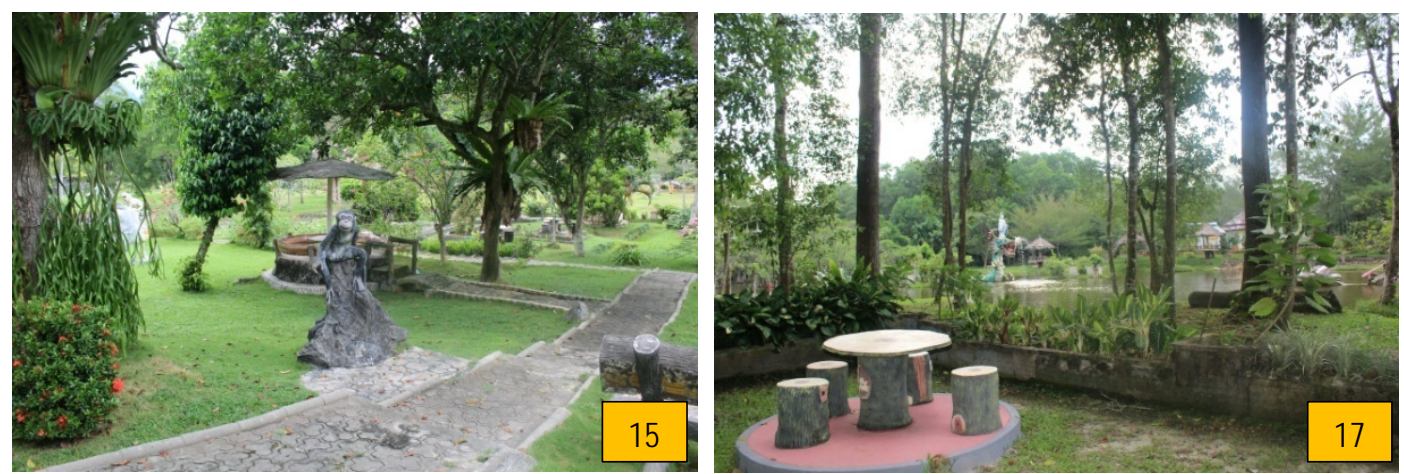

Gambar 6. Lanskap dengan Kualitas Estetika Sedang

\section{c. Lanskap dengan kualitas estetika tinggi}

Lanskap dengan kualitas estetika tinggi terlihat dari proporsi vegetasi yang cukup dominan, sedikit bangunan dengan kualitas fisik yang baik dan menarik. Lanskap 3, lanskap 12, lanskap 19 dan lanskap 20 merupakan lanskap yang memiliki estetika tinggi.

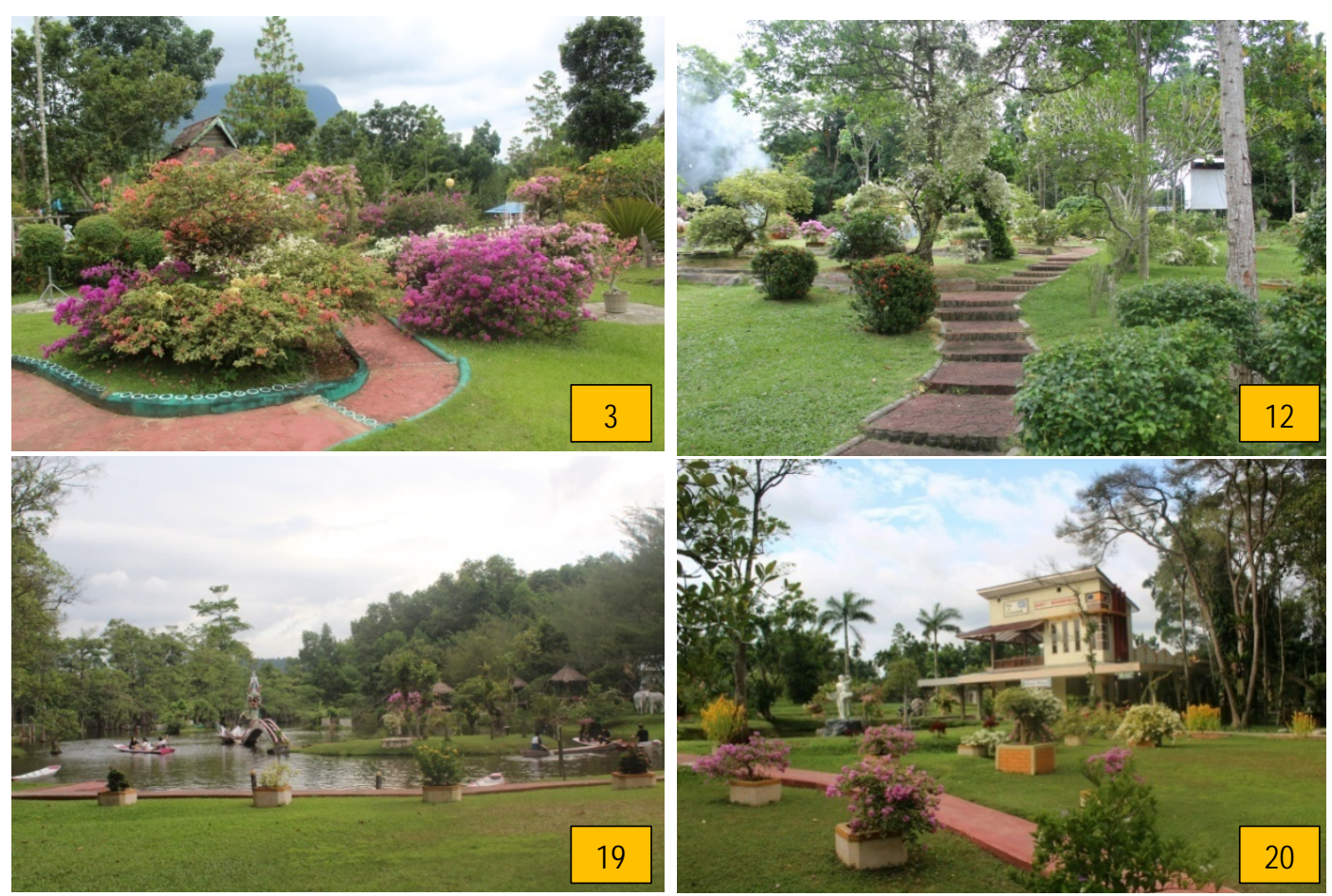

Gambar 7. Lanskap dengan Kualitas Estetika Tinggi

\section{Perbandingan Hasil Penilaian Mahasiswa dengan Hasil Penilaian Pengunjung}

Berdasarkan hasil penilaian mahasiswa dan penilaian pengunjung terhadap Taman Bukit Bougenville menggunakan metode Scenic Beauty Estimation (SBE) terdapat beberapa perbedaan. Perbedaan penilaian mahasiswa dengan penilaian pengunjung terdapat pada lanskap 5, lanskap 9, lanskap 14, lanskap 16 dan lanskap 18. Mahasiswa menilai lanskap 5 dan 9 memiliki kualitas estetika rendah sedangkan pengunjung menilai lanskap 5 dan 9 memiliki kualitas estetika sedang. Pada lanskap 14 mahasiswa menilai lanskap ini sedang sedangkan pengunjung menilainya rendah. Pada lanskap 16 dan 18 mahasiswa menilai lanskap memiliki kualitas estetika tinggi sedangkan pengunjung menilai lanskap memiliki kualitas estetika sedang.

Perbedaan ini terjadi karena adanya perbedaan latar belakang pendidikan responden yang memberikan penilaian. Perbedaan pendidikan merupakan salah satu hal yang mempengaruhi hasil penilaian 
kualitas estetika Taman Bukit Bougenville. Responden mahasiswa memiliki dasar keilmuan yang cukup mengenai lanskap dan estetika lanskap. Selain itu mahasiswa memiliki interaksi yang kuat terhadap variabel keindahan lanskap. Responden mahasiswa memberikan penilaian menggunakan dasar keilmuan lanskap terhadap estetika Taman Bukit Bougenville sedangkan pengunjung Taman Bukit Bougenville memiliki latar belakang pendidikan yang berbeda-beda sehingga interaksi terhadap variabel dan pengetahuan mengenai lanskap tidak sama dan tidak terlalu kuat karena tidak memiliki dasar keilmuan lanskap. Hal ini diperkuat oleh Nasar (1988), bahwa persepsi ditentukan oleh interaksi yang kuat antara variabel lanskap dan pengetahuan terhadap lanskap.

3. Evaluasi Kualitas Lanskap Berdasarkan Daya Dukung Taman Bukit Bougenville

Berdasarkan hasil perhitungan, ambang batas pengunjung Taman Bukit Bougenville yang dapat dilakukan dalam 1 hari adalah 72 orang yang beraktivitas dalam kawasan 6 ha. Jumlah pengunjung yang melebihi ambang batas ini karena adanya event-event berupa perayaan Tahun Baru Masehi, Tahun Baru Imlek, Hari Raya Idul Fitri, Hari Raya Idul Adha dan lain-lain. Berdasarkan data yang diperoleh, diketahui bahwa pada setiap bulan ada jumlah pengunjung yang melebihi ambang batas sehingga akan memberikan dampak seperti : pengunjung merasa tidak nyaman, fasilitas taman menjadi berkurang, lanskapnya bisa rusak, terutama tanaman,tercemarnya udara lingkungan taman, kebersihan taman berkurang.

e. $\quad$ Rekomendasi Pengelolaan Taman Bukit Bougenville

Rekomendasi yang diusulkan berdasarkan hasil penilaian kualitas estetika dan daya dukung Taman Bukit Bougenville seperti : perlunya penambahan papan informasi dan papan himbauan serta pengawasan kepada pengunjung agar fasilitas taman dapat digunakan dengan baik, perlunya penataan pola penanaman pada lanskap berkualitas rendah agar taman terkesan rapi, perlunya pemangkasan tanaman untuk memperbaiki maupun mempertahankan fungsi dan penampilan visual tanaman, membuat alur sirkulasi kunjungan untuk menghindari kepadatan dan penumpukan pengunjung pada satu titik lokasi, menghitung jumlah pengunjung yang masuk dan keluar untuk meminimalisir dampak yang timbul pada zonasi daya tampung taman.

\section{Simpulan}

Hasil evaluasi kualitas lanskap berdasarkan penduga keindahan dan daya dukung Taman Bukit Bougenville menunjukkan bahwa kualitas lanskap masih bagus. Lanskap dengan nilai SBE tinggi memiliki vegetasi dengan penataan baik, indah dan menarik serta rimbun sehingga memberi kesan sejuk dan nyaman. Akan tetapi pada beberapa area memiliki kualitas yang rendah karena didominasi oleh bangunan dengan kualitas fisik yang kurang baik dengan sedikit vegetasi.

Nilai ambang batas untuk jumlah pengunjung Taman Bukit Bougenville yang dapat dilakukan dalam 1 hari adalah 72 orang. Berdasarkan data yang diperoleh, diketahui bahwa pada setiap bulan selama tahun 2016 ada jumlah pengunjung yang melebihi nilai ambang batas. Hal ini berpotensi menimbulkan dampakdampak yang akan mempengaruhi kualitas lanskap.

\section{Daftar Pustaka}

Cifuentes, M. 1992. The Technical Report. Buku. Turrialba. Costa Rica. 194 p.

Daniel, T. C. dan R. S. Boster. 1976. Measuring Landscape Esthethics : The Scenic Beauty Estimation Method. Journal of Landscape Horticlture. 40(2):296-300.

Departemen PU. 2006. Ruang Terbuka Hijau Sebagai Unsur Utama Tata Ruang Kota. Dirjen Penataan Ruang Hendriawati, F. N. 2011. Identifikasi Eco-Aesthetic Lanskap Desa Ancaran, Kabupaten Kuningan [skripsi]. Bogor : Fakultas Pertanian, Institut Pertanian Bogor.

Nassar JL. 1988. Environmental Aesthetic. New York: Cambridge Univ Press.

Ruswan, M. 2006. Analisis Pengaruh Elemen Lanskap Terhadap Kualitas Estetika Lanskap Kota Depok [skripsi]. Bogor: Fakultas Pertanian, Institut Pertanian Bogor. 